\title{
Evaluation of the Cytotoxicity Effect of Dimethyl Sulfoxide (DMSO) on Caco2/TC7 Colon Tumor Cell Cultures
}

\author{
Georges Da Violante, ${ }^{a, b}$ Naima Zerrouk, ${ }^{b}$ Isabelle Richard, ${ }^{a}$ Gérard Provot, ${ }^{a}$ \\ Jean Claude ChaumeIL, ${ }^{b}$ and Philippe ARNAUD ${ }^{*, c}$ \\ ${ }^{a}$ Laboratoire GlaxoSmithkline, New Chemical Entity Unit; 23, rue Lavoisier, ZI n² La Madeleine, 27091 Evreux Cedex 9 , \\ France: ${ }^{b}$ Laboratoire de Pharmacie Galénique, Faculté des Sciences Pharmaceutiques et Biologiques, UPRESS EA 2498 , \\ Université René Descartes; 75006 Paris, France: and ${ }^{c}$ Laboratoire de Pharmacie Galénique, Faculté de Médecine et de \\ Pharmacie, ADEN EA 3234, Université de Rouen; 76183 Rouen, France.
}

Received January 21, 2002; accepted April 19, 2002

\begin{abstract}
Dimethyl sulfoxide (DMSO) is usually used to solubilize poorly soluble drugs in permeation assays such as that using Caco2 enterocyte-like cells. The objective of this study was to evaluate the toxicity of DMSO on Caco2/TC7 cells and determinate the maximal concentration usable in permeation experiments. Caco2/TC7 cells were cultured for $21 \mathrm{~d}$ on 96-well plates for evaluation of toxicity. The determination of lactate dehydrogenase (LDH) release in cell supernatant and the measurement of Neutral Red (NR) uptake are used for cytotoxicity assays. DMSO solutions (0-100\%) in Hank's balanced salt solution containing HEPES (25 mu), pH 7.4, were incubated with Caco-2/TC7 cells on 96 well plates. Caco2/TC7 cells were cultured on Transwell-Clear ${ }^{\circledR}$ inserts to evaluate the influence of DMSO on the apparent permeability of the paracellular marker mannitol. DMSO $10 \%$ did not induce any significant increase in LDH release whereas a significant increase in LDH activity (ANOVA, $p<0.05$ ) occurred at a DMSO concentration of 20 to $50 \%$. NR incorporation in viable cells was statistically reduced by 27 to $36 \%$ at DMSO concentration of $20 \%$ up to $100 \%$ (ANOVA, $p>0.05$ ). No statistical difference $(p<0.05)$ in apparent mannitol permeability was observed between the control and $10 \%$ DMSO groups. In conclusion, at concentrations of up to $10 \%$, DMSO did not produce any significant alteration in apical membrane permeability or on cell-to-cell tight junctional complexes.
\end{abstract}

Key words dimethyl sulfoxide (DMSO); Caco2; cytotoxicity; lactate dehydrogenase; Neutral Red; mannitol

The evaluation of new molecular entities by combinatorial chemistry is a well-known challenge for pharmaceutical companies. In the drug discovery process, poorly-water soluble compounds are often encountered which usually have high lipophilicity. ${ }^{1)}$ In the early stage of drug discovery, radiolabelled compounds are not always available, and the use of low concentrations of these compounds in water often cause several analytical problems when determining their apparent permeability in in vitro permeation assays. Cosolvents, e.g., dimethyl sulfoxide (DMSO) and ethanol, are used to increase the solubility but have some irremediable toxic effects. ${ }^{2}$ The main cosolvent used is DMSO $\left(\mathrm{H}_{3} \mathrm{C}\right)_{2} \mathrm{~S}=\mathrm{O}$ due to its solvent properties, i.e., partly soluble in both aqueous and organic media. ${ }^{3)}$ However, DMSO was reported to interact with the metabolism and membrane of cells, resulting in severe cell damage. ${ }^{4,5)}$

A recent publication ${ }^{6}$ has demonstrated that $5 \%$ DMSO is appropriate in chamber experiments and does not affect the membrane integrity of isolated rat intestinal tissue. In intestinal permeation assays with the enterocyte-like Caco- 2 cell line, the maximal DMSO concentration is $1 \%$ final concentration. $^{7-9)}$ However, there is little information on the nontoxic and maximal usable concentration in $\mathrm{Caco} 2$ cell monolayers in transport studies (incubation time from 2 to $3 \mathrm{~h}$, at $37^{\circ} \mathrm{C}, 10 \% \mathrm{CO}_{2}$, and $95 \%$ relative humidity). Moreover, a previous investigation showed that DMSO could also affect the apparent permeability of lipophilic compounds by underor overestimating their permeability across artificial membranes. ${ }^{1)}$

The aim of the present study was to examine the cytotoxic effect of DMSO on Caco2 cells in transport studies and also to determine its effect on monolayer integrity. The assess- ment of the cytotoxic effects of DMSO was carried out using two well-known methods: lactate dehydrogenase (LDH) release in cell supernatant, ${ }^{10)}$ and incorporation of Neutral Red (NR) uptake in viable cells. ${ }^{11)}$ The effect of DMSO on tight junctions was evaluated by measuring the apparent permeability of mannitol as a function of DMSO concentration on Caco 2/TC7 monolayers.

\section{MATERIALS AND METHODS}

Chemicals DMSO was obtained from Sigma (St Quentin Fallavier, France). $\left[{ }^{14} \mathrm{C}\right]$ mannitol was purchased from NEN-Life Sciences (Les Ulis, France). All culture media were obtained from Life Technologies (Eragny, France). Ninety-six-well microtiter plates and TranswellClear $^{\circledR}$ filters were purchased from Corning Costar (D. Dutcher, Brumath, France). All chemicals were of analytical grade.

Cell Culture $\mathrm{Caco} / \mathrm{TC} 7$ cells were kindly provided by Dr. A. Sweibaum and Dr. M. Rousset (INSERM U170, Villejuif, France) at passage 8 . Cells were monitored as mycoplasma free by polymerase chain reaction (PCR). ${ }^{12)}$ Caco2/TC7 cells were cultured as described by Caro et al. ${ }^{9}{ }^{9}$ Briefly, $0.510^{6}$ cells were seeded on $75 \mathrm{~cm}^{2}$ plastic flasks (Corning Costar) and the medium was completely changed every other day with Dulbecco's modified Eagle's medium (DMEM) supplemented with $10 \%$ of fetal calf serum and $1 \%$ of nonessential aminoacids. Caco2/TC7 cells were incubated in a controlled atmosphere at $37^{\circ} \mathrm{C}, 95 \%$ relative humidity $(\mathrm{RH})$, with $10 \% \mathrm{CO}_{2}$ and reached confluence at $7 \mathrm{~d}$. Cells were seeded on 96-well microtiter plates $(40,000$ cells/well). Every other day the complete medium was changed with 
medium containing DMEM supplemented with $10 \%$ fetal calf serum, $1 \%$ nonessential aminoacids, penicillin (110 $\mathrm{UI} / \mathrm{ml})$, and streptomycin $(110 \mu \mathrm{g} / \mathrm{ml})$. Caco2/TC7 cells were incubated in a controlled atmosphere at $37^{\circ} \mathrm{C}, 95 \% \mathrm{RH}$, and $10 \% \mathrm{CO}_{2}$ and cultured for 21 to $28 \mathrm{~d}{ }^{99}$ For transport studies, $1.510^{6}$ cells were seeded on $24-\mathrm{mm}$ diameter TranswellClear $^{\circledR}$ dishes. The cells were differentiated for 21 to $28 \mathrm{~d}$ in the complete medium supplemented with penicillin (110 $\mathrm{UI} / \mathrm{ml})$ and streptomycin $(110 \mu \mathrm{g} / \mathrm{ml})$.

Cell Death Measurement Working solutions of DMSO were obtained by dilution in fresh Hank's balanced salt solution (HBSS) $/ N-2$ hydroxyethylpiperazine- $N$ '-ethanesulfonic acid (HEPES) (25 mM), $\mathrm{pH} 7.4$, to give final concentrations of $2,4,10,20,50$, and $100 \%$. The negative control was fresh HBSS/HEPES (25 mM), pH 7.4, and the positive control was Triton $^{\circledR}$ X100 (0.1\%) in HBSS/HEPES (25 mM), pH 7.4. Monolayers with approximately $2.10^{5}$ cells/well were incubated with $200 \mu \mathrm{l}$ of each working solution for $2 \mathrm{~h}$ in a controlled atmosphere $\left(37^{\circ} \mathrm{C}, 95 \% \mathrm{RH}, 10 \% \mathrm{CO}_{2}\right)$. Supernatant was withdrawn for investigation of LDH release using the cytotoxicity LDH kit as described by ROCHE Diagnostics (method derived from Jauregui et al. ${ }^{10)}$ )

Preliminary tests have shown LDH activity inhibition at DMSO concentrations of more than $10 \%$. Samples collected with DMSO concentrations of more than $10 \%$ were diluted by $1: 30$ in fresh HBSS/HEPES to avoid LDH inhibition. The cells were washed once in phosphate-buffered saline (PBS) and incubated with NR $(50 \mu \mathrm{g} / \mathrm{ml})$ in HBSS/HEPES $(25 \mathrm{mM}), \mathrm{pH} 7.4$ for $3 \mathrm{~h}$ in a controlled atmosphere. After incubation, the cells were rinsed once in PBS, and NR incorporated in viable cells was extracted with a solution of $50 \%$ $(\mathrm{v} / \mathrm{v})$ ethanol and $1 \%(\mathrm{v} / \mathrm{v})$ acetic acid for $10 \mathrm{~min}$ before measuring optical density at $550 \mathrm{~nm}$ using an ELISA plate reader as described by Faultz et al. ${ }^{11)}$

In Vitro Permeation Study The transport medium was modified HBSS/HEPES ( $25 \mathrm{~mm}$ ), $\mathrm{pH}$ 7.4. The permeability studies were initiated by adding $1.5 \mathrm{ml}$ of fresh buffer with $\left[{ }^{14} \mathrm{C}\right]$ mannitol $(0.2 \mu \mathrm{Ci} / \mathrm{ml})$ into the apical compartment and DMSO at various concentrations up to $10 \%$, and $2.5 \mathrm{ml}$ of fresh buffer was replaced in the basolateral compartment. At time zero, donor solution was withdrawn for quantification of initial counts. The monolayers were incubated at $37^{\circ} \mathrm{C}$ in a controlled atmosphere without shaking for $2 \mathrm{~h}$. At 30 -min intervals, samples $(1 \mathrm{ml})$ were removed from each basolateral compartment and immediately replaced with fresh HBSS/ HEPES (25 mM), pH 7.4.

Data Analysis The apparent permeability values $\left(P_{\text {app }}\right)$ were calculated according to the following equation:

$$
P_{\text {app }}(\mathrm{cm} / \mathrm{s})=\left(\frac{d Q}{d t}\right) \times\left(\frac{1}{A \cdot C_{0}}\right)
$$

where $d Q / d t$ is the flux of drug across the monolayer $(\mathrm{mol} / \mathrm{s})$, $C_{0}$ is the initial concentration in the donor compartment $(\mathrm{mol} / \mathrm{ml})$, and $A$ is the area of the cell monolayer $\left(4.71 \mathrm{~cm}^{2}\right)$. The apparent permeability values are expressed as $\mathrm{cm} / \mathrm{s}$. All data presented are the mean values \pm S.D. of six different filters.

Transepithelial electrical resistance (TEER) values of filter-grown cells were measured using the Millicell-ERS epithelial voltohmmeter (Millipore Co., Bedford, MA, U.S.A.) at various time intervals. The TEER values were calculated according to the following equation:

$$
\operatorname{TEER}\left(\Omega \cdot \mathrm{cm}^{2}\right)=\left(R_{\text {total }}-R_{\text {filter w/o cells }}\right) \cdot A
$$

where $R_{\text {total }}$ is the measured resistance, $R_{\text {filter w/o }}$ cells is the resistance of inserts alone, and $A$ is the surface area. A decrease of greater than $25 \%$ in TEER values compared with the initial readings was taken as an indicator of the loss of monolayer integrity due to DMSO exposure. For $21 \mathrm{~d}$ control cells in HBSS/HEPES ( $25 \mathrm{~mm})$, $\mathrm{pH} 7.4$, the mean TEER value measured was $711 \pm 79 \Omega \cdot \mathrm{cm}^{2}$.

Analytical Assays The concentration of radiolabelled compounds was determined by liquid $\beta$-scintillation counting with quench correction according to single-label mode (Beckman LS 3801, Beckman).

Statistical Analysis Results are expressed as mean \pm S.D. For multiple group analysis of variance, one-factor ANOVA was used. The location of variance was determined using Student's $t$-test in comparison with the control.

\section{RESULTS AND DISCUSSION}

Poorly-water soluble compounds are often encountered during the drug discovery process. In most cases, cosolvents are used to increase the solubility of compounds to perform pharmacokinetic/permeation assays for the selection of new chemical entities with high rates of intestinal absorption with limited analytical problems when radiolabelled compounds are not available. In general, the use of $1 \%$ DMSO increases solubility sufficiently to perform transport studies, but with very highly lipophilic series, the percentage of DMSO must be increased to $5 \%$ or more. In this study, we evaluated the commonly used cosolvent DMSO in Caco2/TC7 permeation assays with two well-known colorimetric methods: determination of LDH release; and incorporation of NR in living cells.

The measurement of LDH in culture supernatant as a result of leakage is an indicator of membrane dysfunction. ${ }^{11)}$ In the present study, increasing concentrations of DMSO up to $100 \%$ were tested. LDH activity released in the supernatant of cultured cells was not statistically different from that in controls at concentrations of up to $10 \%$ DMSO in cultured Caco2/TC7 cells (Fig. 1). DMSO is a low molecular-weight compound (MW 78) reported to interact with cell membranes. DMSO is usually used as a cryoprotectant, and it was also described as an absorption enhancer of sulfadiazine and insulin by the skin. ${ }^{4}$ These observations may explain the increase in LDH release by causing a perturbation of the cell membrane in a concentration-dependent manner which was statistically significant by 2 -fold and 12 -fold at 20 and $50 \%$ DMSO, respectively (Fig. 1). In the present study, it was not possible to show the cytotoxic effect of $100 \%$ DMSO. A previous study demonstrated that DMSO inhibits acetylcholinesterase activity by altering protein configuration. These observations could explain the inhibition of LDH activity compared with untreated cells when cultured with $100 \%$ DMSO. $^{13)}$

The evaluation of NR uptake in living cells as an indicator of xenobiotic toxic effects has been well documented. ${ }^{11,14)}$ NR is a weakly cationic dye that penetrates into cells by nonionic diffusion. NR is taken up in the lysosomes of living 


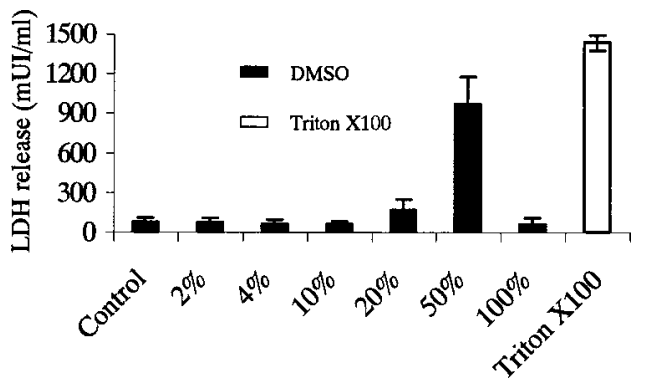

Fig. 1. LDH Activity Release from Caco-2/TC7 Cells Cultured on 96Well Microtiter Plates as a Function of Percentage of DMSO in HBSS/HEPES (25 mM), pH 7.4

Results are expressed as mean \pm S.D. of six independent wells

cells as described by Faultz et al. ${ }^{11)}$ However, the mechanism of penetration into lysosomes, active or passive, remains unclear. The toxicity data were obtained by treating six independent cultures with each concentration of DMSO. All concentrations yielded concentration-related cytotoxic effects as evidenced by decreased NR uptake and decreased $\mathrm{OD}_{550}$ values. The cytotoxicity data obtained are listed in Table 1 . The percentage of viable cells relative to the current negative control was calculated to facilitate the comparison of the results under different conditions. When cells are exposed to increased concentrations of DMSO, a significant decrease in NR uptake $\left(\mathrm{OD}_{550}\right)$ occurs as shown in Table 1 . When compared with the control, the NR90 described as the limiting indicator of living cell cultures ${ }^{14)}$ appeared at DMSO concentrations between 10 and $20 \%$. The percentage of viable cells is reduced from 100 to $73 \%$ for the negative control at DMSO $20 \%$ whereas at DMSO $10 \%$ NR uptake remained unchanged (ANOVA, $p>0.05$ ). The 100\% DMSO-treated cells were used as positive controls for toxicity because almost no cells are viable under such conditions. ${ }^{15)}$ Surprisingly, this concentration did not result in a high rate of cell death.

The validity of the NR uptake experiment was controlled by using an aqueous solution of Triton X100 $(1 \% \mathrm{~m} / \mathrm{v})$ as a positive control for cell toxicity. Our results showed an NR uptake rate of $17 \%$ after 120-min exposure (Table 1). Previous studies showed that the viability of cells exposed to DMSO is dependent on the length of exposure and the cell line. ${ }^{16,17)}$ Branch et al. ${ }^{17)}$ showed that hematopoietic progenitor cells especially colony-forming units granulocyte/ macrophage (CFU-GM), are not affected after exposure to DMSO $(8.5 \% \mathrm{vol} / \mathrm{vol})$ for $120 \mathrm{~min}$. In contrast, the viability of some mononuclear cells decreased within time of exposure to DMSO solutions $(8.5 \% \mathrm{vol} / \mathrm{vol})$, as determined by trypan blue dye-exclusion assay. Malinin et al. ${ }^{16)}$ reported that exposure of $\mathrm{HeLa}$ cells to DMSO concentrations of more than $5-10 \%$ results in the appearance of abnormal cells independent of the length of exposure. Under our conditions, the Caco2/TC7 cells were resistant to organic solvent exposure, at least for $120 \mathrm{~min}$. The NR assay and the measure of LDH release were well correlated $\left(p<0.05, r^{2}=0.88\right)$ for DMSO concentrations up to $50 \%$, suggesting the same degree of cytotoxic effect of DMSO on Caco2/TC7 cell monolayers.

In permeation assays, the monolayer integrity is determined by TEER measurement and also by determining the
Table 1. Cytotoxicity of DMSO on Adenocarcinoma of Colon Tumor Caco2/TC7 Cells

\begin{tabular}{ccc}
\hline \hline $\begin{array}{c}\text { Concentration } \\
(\mathrm{DMSO} \% \mathrm{v} / \mathrm{v})\end{array}$ & $\begin{array}{c}\text { Neutral red absorption } \\
\left(\mathrm{OD}_{550}\right) \\
(\text { mean } \pm \text { S.D. })^{d)}\end{array}$ & $\begin{array}{c}\text { Percentage of } \\
\text { viable cells })^{c}\end{array}$ \\
\hline Negative control $^{a)}$ & $0.850 \pm 0.098$ & 100 \\
2.0 & $0.971 \pm 0.190$ & 114 \\
4.0 & $0.931 \pm 0.085$ & 109 \\
10.0 & $0.886 \pm 0.037$ & 104 \\
20.0 & $0.624 \pm 0.014$ & 73 \\
50.0 & $0.511 \pm 0.087$ & 60 \\
100.0 & $0.552 \pm 0.103$ & 64 \\
Positive control $^{b)}$ & $0.141 \pm 0.041$ & 17
\end{tabular}

Caco-2/TC7 cells were treated with the chemical for $2 \mathrm{~h}$ before the NR test. $a$ ) Fresh HBSS/HEPES $(25 \mathrm{~mm}), \mathrm{pH} 7.4$ (negative control). $b$ ) Triton X100 (0.1\%) in HBSS/HEPES (25 mM), pH 7.4 (positive control). c) Values calculated relative to the negative control. d) Values represent mean \pm S.D. of 6 independent cultures.

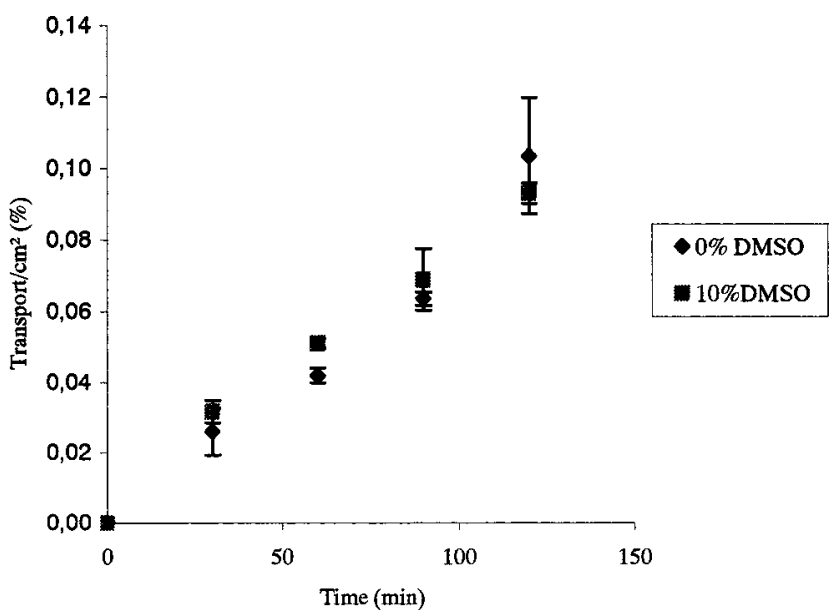

Fig. 2. Percentage of Mannitol Transported across Caco-2/TC7 Cell Monolayers as a Function of Time and DMSO Concentration

Bars indicate mean \pm S.D. of three independent wells.

apparent mannitol permeability as markers of monolayer integrity. ${ }^{18)}$ In the present study, we evaluated these to investigate the influence of DMSO on the cell monolayer. A cytotoxic effect of high concentrations of DMSO may induce monolayer disruption and an alteration of cell-to-cell tight junctional complexes. In transport studies, such phenomena could result in an increase in the transport of the test compound and induce an overestimation of its apparent permeability. The percentage of mannitol transported across the Caco-2/TC7 monolayers as a function of time and DMSO concentration (\%) are indicated in Fig. 2. The concentrations of DMSO chosen for transport studies were well within the safety limit (10\%) which was deduced from the LDH release and NR uptake. With DMSO $(10 \% \mathrm{vol} / \mathrm{vol})$, the percentage of mannitol transported across $\mathrm{Caco} 2 / \mathrm{TC} 7$ cell monolayers for $2 \mathrm{~h}$ were not statistically increased when compared with the negative control (fresh HBSS/HEPES [25 mM], pH 7.4) (ANOVA, $p>0.05$ ). These results correlate well with the TEER values measured after 120-min exposure to DMSO $(10 \%)$, which did not result in a decrease of more than $25 \%$ of the TEER control value described as the safety limit for transport studies. ${ }^{18)}$ This indicates that no marked alteration of the Caco2/TC7 cell monolayers occurred with DMSO 
$(10 \% \mathrm{vol} / \mathrm{vol})$ up to 120 -min exposure, which is compatible with permeation assays conducted for new synthesize compounds. However, a recently published study indicated that the use of high concentrations of DMSO (from $4 \%$ to $10 \%$ ) could reduce the transepithelial permeability coefficient of $\left[{ }^{3} \mathrm{H}\right]$ dexamethasone, underestimating the drug permeability through Caco2 monolayers. ${ }^{2)}$ The permeability of dexamethasone is controlled by its partition coefficient between DMSO and the cellular membrane of cells. Thus, in spite of its apparent nontoxicity at $10 \%$, DMSO could induce artifacts in the determination of transepithelial transport of drugs. The present results should be followed up by studying the impact of DMSO concentrations up to $10 \%$ on the apparent permeability of drug compounds for which the absorption mechanism though the intestinal membrane is wellknown to optimize the conditions of intestinal transport studies.

\section{CONCLUSION}

DMSO may be used at higher concentrations (up to $10 \%$ ) than those reported in the literature in $\mathrm{Caco} 2 / \mathrm{TC} 7$ cells without any significant cell damage. However, other cytotoxicity assays could be performed for a better understanding of DMSO toxicity. Some metabolic effects of DMSO could not be detected using the present methods, although they may have been present. Moreover, these results should be followed by an evaluation of the effects of high concentrations in DMSO on the apparent permeability of well-known compounds. Although the concentrations used here were not cytotoxic, they may induce an increase or decrease in the intestinal transport of drugs. These features must be studied in detail to avoid over- or underestimation of human intestinal absorption.

\section{REFERENCES}

1) Sugano K., Hamada H., Machida M., Ushio H., Saitoh K., Terada K., Int. J. Pharmaceut., 228, 181-188 (2001).

2) Yamashita S., Furubayashi T., Kataoka M., Sakane T., Sezaki H., Tokuda H., Eur. J. Pharm. Sci., 10, 195-204 (2000).

3) Stammati A., Zampaglioni F., Zucco F., Cell. Biol. Toxicol., 13, 125130 (1996).

4) Brayton C. F., Review Cornell Vet., 76, 61-90 (1986).

5) Penninckx F., Cheng N., Kerremans R., Van Damme B., De Loecker W., Cryobiology, 20, 51-60 (1983).

6) Watanabe E., Sudo R., Takahashi M., Hayashi M., Biol. Pharm. Bull., 23, 838-843 (2000).

7) Artursson P., Karlsson J., Biochem. Biophys. Res. Commun., 175, 880 -885 (1991).

8) Irvine J. D., Takahashi L., Lockhart K., Cheong J., Tolan J. W., Selick H. E., Grove J. R., J. Pharm. Sci., 88, 28-33 (1999).

9) Caro I., Boulenc X., Rousset M., Meunier V., Bourrié M., Julian B., Joyeux H., Roques C., Berger Y., Zweibaum A., Fabre G., Int. J. Pharmaceut., 116, 147-158 (1995).

10) Jauregui H. O., Hayner N. T., Driscoll J. L., Williams-Holand R., Lipky M. H., Galletti P. M., Fund. Appl. Toxicol., 2, 139-144 (1981).

11) Faultz R., Husein B., Hechenberger C., Mutation Res., 253, 173-179 (1991).

12) Rawadi G., Dussurget O., Genome Res., 4, 199-208 (1995).

13) Sams W. M., Jr., Ann. N. Y. Acad. Sci., 141, 242-247 (1967).

14) Borenfreund E., Puerner J., Toxicol. Lett., 24, 119-124 (1985).

15) Rammler D. H., Ann. N. Y. Acad. Sci., 141, 291-299 (1967).

16) Malinin T. I., Vernon P. P., Cryobiology, 4, 90-96 (1967).

17) Branch D. R., Calderwood S., Cecutti M. A., Herst R., Solh H., Transfusion, 34, 887-890 (1994).

18) Boisset M., Botham R. P., Haegele K. D., Lenfant B., Pachot J., Eur. J. Pharm. Sci., 10, 215-224 (2000). 